\title{
DA PARTICIPAÇÃO DE MULHERES NO FUTEBOL EM BARBACENA/MG NAS TRÊS PRIMEIRAS DÉCADAS DO SÉCULO XX1
}

\author{
Recebido em: 22/10/2019
}

Aprovado em: 25/04/2020

Licença: @) (1) @

Igor Maciel Silva2

Maria Cristina Rosa3

Universidade Federal de Minas Gerais (UFMG)

Belo Horizonte - MG - Brasil

\begin{abstract}
RESUMO: Este artigo busca compreender como mulheres de Barbacena/MG participaram do futebol nas primeiras décadas do século XX. Realizou-se pesquisa documental na Hemeroteca Histórica da Biblioteca Pública Estadual Luiz de Bessa, em Belo Horizonte, no jornal Cidade de Barbacena. O futebol manifestou-se de diferentes formas: times foram organizados, campos inaugurados, jogos realizados e sedes sociais de clubes construídas. As mulheres, sobretudo jovens pertencentes a estratos sociais mais privilegiados economicamente, participaram como assistentes-espectadoras e assistentes-torcedoras responsáveis pelo lance inicial de partidas, pela entrega de premiação à equipe vencedora e como madrinha de time. Essas formas de participação não se opuseram ou se permutaram e podem ter possibilitado, com a presença da mulher em campo, outras configurações para um esporte destinado então apenas aos homens.
\end{abstract}

PALAVRAS-CHAVE: Mulheres. Atividades de Lazer. Futebol.

\section{OF WOMEN'S PARTICIPATION IN FOOTBALL IN BARBACENA/MG IN THE FIRST DECADES OF THE 20th CENTURY}

ABSTRACT: This article seeks to understand how women from Barbacena / MG participated in soocer in the first decades of the twentieth century. Documentary research was carried out at the Historical Hemeroteca of the Luiz de Bessa State Public Library, in Belo Horizonte and in the "Cidade de Barbacena" newspaper. Soocer manifested itself in different ways: teams were organized, pitches inaugurated, matches played and club headquarters were built. The women, especially young ones from the most economically privileged social strata, participated as spectator assistants and fan assistants, responsible for the initial launch of matches, the awarding of the winning team and as a team godmother. These forms of participation haven't been opposed to or

\footnotetext{
1 Este estudo contou com financiamento da Coordenação de Aperfeiçoamento de Pessoal de Nível Superior (CAPES). Agradecemos ao barbacenense Robson Ferreira por auxiliar na investigação de fotografias de Barbacena no início do século XX e à família Duque-Estrada pela cessão de documentos que ajudaram a compreender a história do futebol em Barbacena.

2 Doutorando e Mestre pelo Programa de Pós-Graduação Interdisciplinar em Estudos do Lazer da UFMG.

3 Professora Associada do Departamento de Educação Física e do Programa de Pós-Graduação Interdisciplinar em Estudos do Lazer da UFMG. Mestre e Doutora pela Universidade Estadual de Campinas (UNICAMP).
} 
changed themselves and may have enabled, with women's presence in the field, other configurations for a sport intended only for men.

KEYWORDS: Women. Leisure Activities. Soccer.

\section{Introdução}

Nos anos finais do século XIX e, sobretudo, no início do século XX, muitas cidades brasileiras viveram um momento de reconfiguração urbana de seus perímetros mediante a chegada de energia elétrica, a fundação de indústrias para atender os mais diversificados setores, a reestruturação do mercado de trabalho e a abertura de vias férreas e terrestres conectando cidades de aspectos interioranos a grandes centros comerciais, como Rio de Janeiro e São Paulo (AMARAL, 2016; AMARAL; DIAS, 2017). Também foi característica desse período a reorganização de espaços públicos para a promoção de diversas formas de sociabilidades4, a fim de se instituir costumes e práticas já vivenciadas em lugares considerados prósperos econômica e culturalmente, como França, Inglaterra e Estados Unidos (SEVCENKO, 1992; LUCENA, 2001; DEL PRIORE, 2017).

Nesse período, Barbacena, cidade mineira localizada na microrregião de Campo da Mantiqueira, como outros municípios do Estado (RODRIGUES, 2006; BARROS, 2005; BARROS, 2008; SOARES, 2010; SILVA, 2012; SOUTTO MAYOR, 2017), aderia às novidades em voga: indústrias e fábricas foram inauguradas e houve investimentos na infraestrutura urbana mediante a abertura de vias para automóveis, ampliação da linha férrea já existente na região, iluminação elétrica de espaço público, higienização e calçamento de ruas, reforma de praças e construção de lugares destinados ao entretenimento (SILVA, 2018).

\footnotetext{
4 Sociabilidade é a interação entre pessoas que por propósitos em comum podem ser percebidas como
} unidades, como grupos específicos. Para melhor entendimento consultar Simmel (1983). 
Essas e outras mudanças na vida citadina brasileira influenciaram diretamente nos comportamentos das pessoas. Para as mulheres - que até meados dos anos finais do século XIX permaneciam de forma mais intensa no espaço privado, seja em atividades domésticas ou relacionadas ao matrimônio ou na vivência de distrações, como festas de aniversários, comemorações de casamentos e bodas, recitais particulares de música e literatura - foi possibilitado, por exemplo, maior mobilidade social e aproveitamento dos espaços públicos e das práticas desempenhadas (MALUF; MOTT, 1998; GOELLNER, 2008), o que permitiu a constituição de novas formas de divertimento para elas (TRINDADE, 1996; MALUF; MOTT, 1998; GOELLNER, 1999; MELO, 2001).

Barbacena, nos anos iniciais do século XX, abrigava vários divertimentos, muitos marcados por encontros sociais, como: footing 5 ; cinema; concertos musicais; retretas; vesperatas; espetáculos teatrais e circenses; festas beneficentes, cívicas, religiosas, campestres e literárias; bailes e chás dansantes6; bailes de carnaval; kermesses, concursos de elegância e beleza e exposição pastoril.7

Esportes e jogos estavam muito presentes na agenda dos divertimentos barbacenenses. Entre as instituições responsáveis pela organização e realização dessas atividades destacam-se Sub-Liga Queluziana de Desportos Terrestres, o Grupo dos Escoteiros do Gymnasio Mineiro, a Associação Barbacenense de Escoteiros e o Clube de Tiro e de Corrida de Cavalos. Também foram localizadas instituições destinadas ao futebol, como os clubes Olympic Football Club e Democrata Foot-ball Club, que abrigavam em seu cotidiano partidas ludopedicas e outras práticas corporais.

\footnotetext{
5 O footing foi uma prática de encontro, muito comum na primeira metade do século XX no Brasil, que tinha como principal finalidade o flerte entre homens e mulheres enquanto caminhavam por ruas, praças e portas de cinema (SILVA, 2002).

6 Optou-se por manter a ortografia de alguns termos e expressões, conforme a fonte consultada.

7 Muitas dessas práticas se instauraram em Barbacena em anos anteriores, sendo necessárias pesquisas. No momento sabe-se que nos anos finais do século XIX aconteceram na cidade apresentações de circo (DUARTE, 1995) e organização de festas religiosas (RESSAQUINHA, 1893).
} 
As mulheres participavam desses e de outros divertimentos de formas distintas, principalmente como assistentes, ou seja, na posição de espectadoras de encenações teatrais, de apresentações musicais e de filmes e espetáculos esportivos, como cavalhadas e corridas de cavalos; como organizadoras de festividades em eventos beneficentes e bailes de danças, por exemplo; como artistas amadoras em recitais e apresentações de música e teatro; como rainha e granduquezas 8 do escotismo; como praticantes de atletismo, patinação, danças e gymnastica rythmada; e como protagonistas do footing da rua XV de Novembro e adjacências (SILVA, 2018).

Nos esportes, ainda que as instituições ou associações esportivas comumente direcionassem a prática das modalidades aos homens, as mulheres também participavam.

Este artigo busca compreender as formas de participação das mulheres no futebol em Barbacena/MG, nas três primeiras décadas do século XX. As perguntas centrais são: como o futebol manifestava-se nessa localidade? Como era a participação das mulheres e quem eram essas mulheres? Quais sentidos e significados foram atribuídos à participação das mesmas nesse esporte cuja prática era permitida apenas aos homens?

Foi feita pesquisa documental na Hemeroteca Histórica da Biblioteca Pública Estadual Luiz de Bessa, em Belo Horizonte/MG, sendo o jornal Cidade de Barbacena o documento9 privilegiado por ser considerado o de maior circulação em Barbacena no período de 1898 a 1993 (SAVASSI, 1991; RESENDE, 2012) e estar disponibilizado no acervo consultado, tornando acessível.

${ }_{8} \mathrm{O}$ termo granduquezas faz alusão a um título nobre que é inferior ao posto de princesa (MICHAELIS, 2019).

9 Documento é considerado como testemunho escrito do passado, pode ser entendido como prova histórica e também como vestígio, como, por exemplo, jornais, revistas e leis oficiais (LE GOFF, 2013; BLOCH, 2001). 
A importância de ter a imprensa periódica como fonte se dá porque o jornal é considerado o documento de maior periodicidade e com informações das mais diversificadas a respeito da vida citadina de diversas regiões no início do século XX (ZICMAN, 1985; CUNHA JUNIOR et al, 2011), características essas que possibilitam um melhor conhecimento da sociedade barbacenense nos âmbitos político, social, cultural e econômico (RESENDE, 2012).

O jornal é também um importante documento para entender "o lugar reservado às mulheres em diferentes épocas" (DE LUCA, 2011, p. 126) e em distintas práticas, como no futebol, como ocorre neste artigo.

O futebol nos anos iniciais do século XX, em Minas Gerais, tem sido objeto recorrente de estudos historiográficos sobre divertimentos, devido entre outros fatores a sua importante contribuição na constituição do campo esportivo no Estado.10 Todavia, pesquisas que versam sobre a participação das mulheres nessa modalidade esportiva ainda constam em número reduzido.

Algumas narrativas historiográficas indicam a presença delas na dinâmica da vida dos times, como assistentes-espectadoras e assistentes-torcedoras, todavia não tematizam a mulher e o futebol como tema específico, não refletindo, pois, de maneira aprofundada sobre as formas de participação das mesmas nesse divertimento. Alguns exemplos:

Souza Neto (2010) ao investigar sobre a invenção do torcer em Belo Horizonte entre 1904 e 1930 mostra que mulheres estiveram em campos, torcidas e festas organizadas por times da cidade. Soutto Mayor (2017), ao analisar o amadorismo e o profissionalismo do futebol nas décadas de 1930 e 1940 também em Belo Horizonte, cita de modo similar a participação de mulheres em torcidas nos dias de jogos. 
O mesmo ocorre em investigações que tratam de outras cidades mineiras, como o trabalho de Amaral (2016) que, ao averiguar a introdução clubística e a consolidação dos sentidos de competitividade do foot-ball no centro-oeste mineiro entre 1888 e 1930 , ressalta a participação de mulheres dessa região como integrantes das arquibancadas nos dias das partidas. Silva (2017) também apresenta que em Uberlândia e Uberaba, cidades do Triângulo Mineiro, entre 1918 e 1943, entre os divertimentos, práticas corporais e esportivas, as citadinas estavam nas arquibancadas, na torcida de times de futebol dessas localidades, como também em concursos que as elevaram ao posto de rainhas de equipes de futebol de Uberlândia.

Entre as poucas pesquisas sobre mulher e futebol em Minas Gerais, destaca-se o trabalho de Campos (2010), que buscou conhecer o perfil das torcedoras da equipe do time de futebol belo-horizontino Cruzeiro Esporte Clube na dinâmica dos jogos sediados no estádio Governador Magalhães Pinto (Mineirão) em 2009.

Sobre o futebol em Barbacena não foram encontrados estudos específicos, como também são poucas as investigações historiográficas sobre a história dos divertimentos nessa região (SILVA, 2018). Além disso, Barbacena é comumente retratada em trabalhos acadêmicos apenas como um lugar que abrigou hospitais e manicômios, como o Hospital Colônia onde ocorreu o holocausto brasileiro, ou seja, o extermínio de pacientes que ao invés de terem progresso em seus tratamentos eram conduzidos ao óbito (ARBEX, 2013; CIMINO, 2013). Pesquisas que valorizem a diversidade cultural da cidade, destacando-a por meio de outras temáticas são importantes, pois contribuem para a escrita de outras narrativas, diversas e plurais, do município.

Para mais, existe uma lacuna no que diz respeito a produções científicas sobre Barbacena que demarquem como recorte temporal as décadas iniciais do século $\mathrm{XX}$ 
(PIMENTA, 2015), e que, do mesmo modo, investiguem os divertimentos da cidade (SILVA, 2018; PIMENTA, 2015).

\section{Sobre Futebol em Barbacena}

Foram identificadas na cidade diversas ações relacionadas ao futebol, como a existência de times; a construção de campos; a inauguração de sedes sociais de clubes de futebol para o entretenimento dos seus sócios por meio da oferta de diversificados entretenimentos e a realização de partidas e torneios de futebol contando com a participação de equipes da cidade bem como de outros municípios, como Belo Horizonte (MATCH DE FOOT-BALL, 1917, n. 1320, p. 1) e Uberaba (SILVA; LIMA, 2016), revelando uma importante mobilização das pessoas em torno dessa prática que, como em outras cidades de Minas Gerais, era algo crescente no início do século XX (DIAS et al, 2014; SOUZA NETO, 2010; SOUTTO MAYOR, 2017). Todos esses indícios ajudam a compreender um pouco a dinâmica não só do futebol na cidade como de outros divertimentos.

Já no primeiro decênio do século XX existiam times de futebol barbacenenses (SAVASSI, 1991; SOARES, 2010; CUNHA JUNIOR et al, 2011) que disputavam até com equipes de Belo Horizonte, como ocorreu em outubro de 1904, no jogo entre o barbacenense Hugo Braga Futebol Clube e o belo-horizontino Victor Serpa Futebol Clube (SAVASSI, 1991). Além disso, equipes locais iam para outras cidades para jogar, como na partida sediada em solo juizforano, em novembro de 1907, entre o barbacenense Dr. Cunha Foot-ball Club e a equipe do Athletico Club Granberyense de Juiz de Fora (SOARES, 2010; CUNHA JUNIOR et al, 2011). 
Entre os locais para a prática do futebol foram identificados alguns campos, como o do Collegio Millitar e o do Olympic Football Club e, consequentemente, equipes formadas. O Collegio Millitar de Barbacena funcionou entre 1913 e os anos iniciais da década de 192011 como um espaço de formação de pessoas do sexo masculino para se candidatar em cursos militares superiores (MASSENA, 1985). O Colégio possuía em seu perímetro um campo de futebol, assim como equipes, sendo elas o Paysandú F. C., o Mayrink F. C. e o Ituiti (SAVASSI, 1991).

Já o campo do Olympic Football Club pertenceu a um time de futebol com o mesmo nome, fundado em 25 de julho de 1915, sendo ativo até o tempo presente. De início este campo funcionava no Gymnasio e, posteriormente, com a aquisição do Velódromo existente no Morro de Santa Thereza12, o clube construiu neste local, na década de 1920, o seu campo definitivo (SAVASSI, 1991).

Em 1922, em uma peleja ludopedica realizada em comemoração aos sete anos de vida do Olympic Foot-ball Club, o seu time de futebol jogou contra o Mangueira Foot-Ball Club. No fim dos páreos, os jovens barbacenenses vencedores (Othon Burlamarque, Cyro Estrada, José Lima, João Pereira Antonio Diniz, Arthur Russo, Francisquinho Dutra e Archimedes Alvez) receberam prêmios oferecidos pelos patronos do time frente à assistência que lhes concedeu aplausos (FOOT-BALL, 1922, n. 1814, p. 1).

Alguns membros dessa equipe permaneceram por mais alguns anos, como pode ser observado na fotografia abaixo (FIGURA 1), referente a uma partida realizada em Belo Horizonte em 1924 entre o Olympic Foot-ball Club e o Athletico Club Mineiro, em

\footnotetext{
11 Segundo Massena (1985), o Collegio Millitar funcionou até 1923, já Savassi (1991) aponta que a data de encerramento das atividades foi em 1925.

12 O Morro de Santa Thereza, de propriedade de Orlando Piergentilli, um italiano radicado em Barbacena, é considerado um dos lugares pioneiros da cidade destinados ao entretenimento. No local existia um velódromo, um rinque de patinação e um salão que abrigava eventos, como bailes de danças (PIMENTA, 2015; SILVA, 2018). A inauguração e o funcionamento desse morro carecem de pesquisas, devido a sua importância neste contexto.
} 
que constam os jogadores Cyro Duque Estrada (penúltimo da esquerda para a direita), José Lima (sexto da esquerda para a direita) e Arthur Russo (sétimo da esquerda para a direita).

\section{Figura 1: Jogadores do Olympic Foot-Ball Club (1924).}

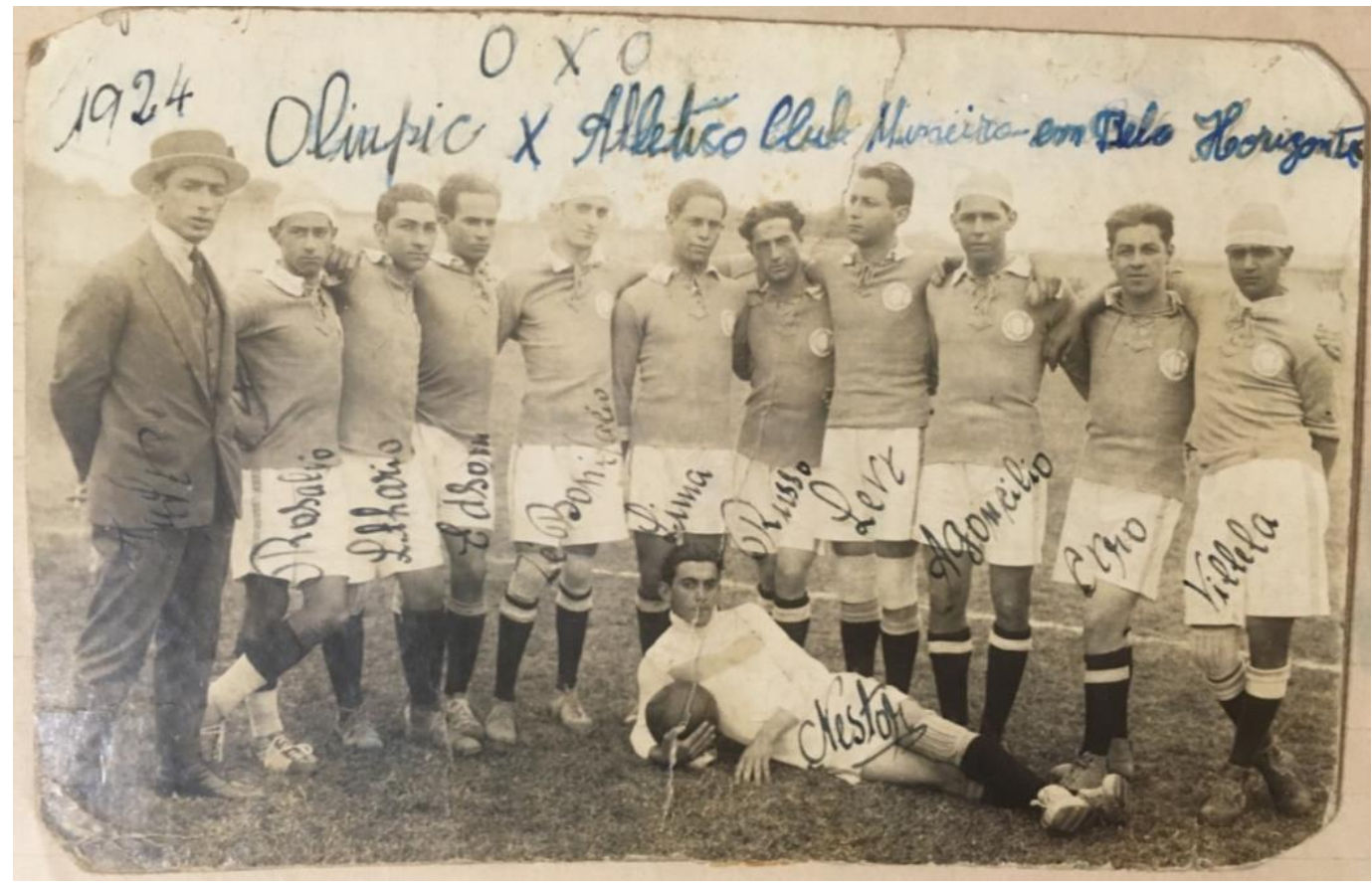

Fonte: Acervo pessoal da família de Cyro Duque Estrada.

Cyro Duque Estrada é considerado o principal recordista de tentos do Olympic de sua época, o que lhe rendeu o duplo título de campeão do time, conforme indica a reportagem Veteranos empoeirados, assinada por “O. SO”” (O. SÓ’, 1940). Todavia, nessa época ele era lembrado no meio esportivo apenas pela glória de seu passado, restando-lhe atribuição de honra, pois o sobrepeso de seu corpo, supostamente por excessos alimentares, condenara-o ao declínio de suas habilidades de jogar futebol.13

13 O. SÓ’. Veteranos empoeirados, Barbacena, agosto de 1940. Algumas fontes serão citadas em nota de rodapé pois os seus dados estão incompletos, por exemplo, a referência ao nome do documento ou dos documentos em que foram publicadas. Tratam-se de recortes que foram cedidos pela família de Cyro Duque Estrada. Devido a importância das informações desse material optou-se por tê-los como fonte, 
Aliás, Cyro é uma pessoa interessante: filho de Osorio Duque Estrada, autor da letra do Hino Nacional Brasileiro e fundador do Clube de Nudismo de Cataguases/MG em 1912 (SOARES, 2018), é natural de Petrópolis, nasceu em 18 de junho de 1901 e morreu em 6 de agosto de 1958. Trabalhou na Escola Agrícola de Barbacena14, também foi escriturário, vereador e delegado na cidade. 15

Não se sabe como foi a sua inserção no Olympic Foot-ball Club, apenas que estava presente desde os primeiros anos de existência do clube e que participou tanto do seu time oficial quanto de equipes que competiram em campeonatos internos organizados pelo próprio clube. Todavia, a sua relação com o Olympic e com os esportes merecem maiores investigações, pois além de atuar em diferentes posições em campo, ele também foi juiz oficial da Sub-Liga Queluziana de Desportos Terrestres (FIGURA 2).

Figura 2: Cyro Duque Estrada na Sub Liga Queluziana de Desportos Terrestres (s.d.).

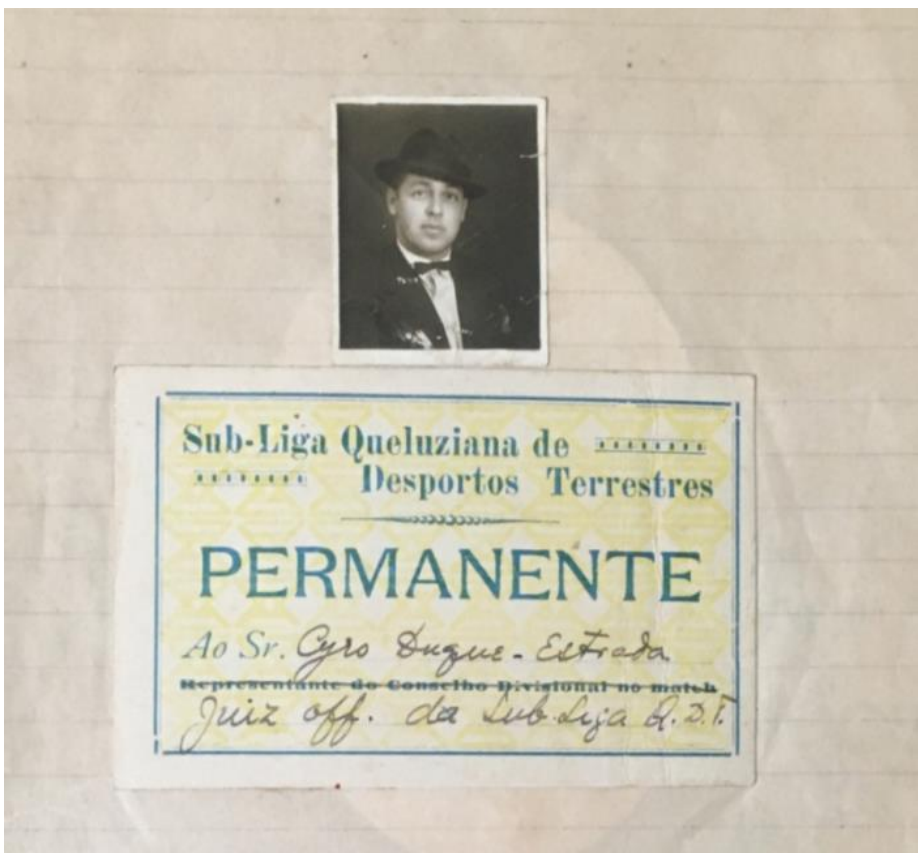

contudo a referência será citada em nota de rodapé, visto a ausência de dados completos, diferente das que estão no tópico 'Referências' deste artigo.

14 Para mais detalhes sobre a Escola Agrícola de Barbacena consultar Cimino (2013).

15 NOVO DELEGADO CIVIL DE BARBACENA, ...; FALECIMENTOS CYRO DUQUE ESTRADA, 6 ago 1958... . 
Fonte: Acervo pessoal da família de Cyro Duque Estrada.

No Olimpic a participação de Cyro é tão representativa que em 1957 o programa de auditório Programascope conferiu a ele o diploma de Honra ao Mérito pelos serviços prestados ao Olimpic Football Club e ao esporte barbacenense (DIPLOMA, 1957).16

Além do campo de futebol, o Olympic também possuía uma sede social, inicialmente inaugurada em 1923 no sobrado da rua 15 de novembro, onde antes funcionava um clube recreativo, o Club Barbacenense. Nesse local os sócios tinham acesso a:

[...] uma sala para exercicios gymnasticos, com os apparelhos adequados; sala de bilhares; rink para lucta romana e box; sala para jogos de salão; mesas de ping-pong, damas, xadrez, etc. E' tambem pensamento da Directoria organisar uma biblioteca, installando-a no compartimento agora destinado á leitura de jornaes e revistas, com o louvavel proposito de facilitar tambem o desenvolvimento intellectual dos socios, promovendo igualmente a realização de conferenciaes sobre themas moraes-sociaes, physico-hygienicos e sportivos em geral. Todas estas dependencias serão localisadas nas salas internas, ficando as da frente reservadas ao gabinete do presidente, secretaria e thesouraria, e o amplo salão exclusivamente destinado ás recepções e reuniões sociaes (CALVO, 1923, n. 1894, p. 2).

Em 1927 essa sede social foi transferida para o palacete Raul Penido. Essa mudança foi citada por Calvo, colunista do jornal Cidade de Barbacena, como uma atitude que muito concorreria para o progresso do Olympic-Club devido à centralidade que o palacete tinha, ou seja, devido o prédio ser "muito central" a acessibilidade dos sócios do Olympic poderia ser mais bem possibilitada e, assim, a vida de sua sede social ser perpetuada (CALVO, 1927, n. 2299, p. 2).

Pistas sobre outros times de futebol, para além das equipes desses dois clubes, foram encontradas em Barbacena nas três primeiras décadas do século XX, como o

16 Para mais, constam informações de que em meados de 1930 e 1940 Cyro foi ator em Barbacena, compondo equipe de amadores, como a Troupe Réco-Réco, que tinha direção artística de seu irmão, Saulo Duque Estrada, a qual obteve destaque na cidade e em outras localidades, como em São João d'el Rei. Este evento que ressalta a presença de Cyro não somente nos esportes, mas também em outros divertimentos da cidade (CORREIO TEATRAL. São João del-Rei, ...; THEATRO S. JOSÉ, 25 fev. 1932...; THEATRO S. JOSÉ, 29 mar. 1932 ....; CINE THEATRO BRASIL, maio de 1940... ). 
Independente, o Floriano, o Yale, o Villa Nova, o Iris, o Campista, o Villa do Carmo S. $C$ e o America $F$. C. (SAVASSI, 1991). Todavia, não foram localizados maiores detalhes sobre os mesmos, além dos poucos que se referem ao Democrata Foot-ball Club, time do Bairro do Sanatório.

Esta agremiação possuía também uma sede social em que mulheres participavam de bailes de dança que terminavam altas horas da madrugada ou ao amanhecer do outro dia (SOCIAES, 1931, n. 2645, p. 3) e de bailes de carnaval cuja entrada parecia ser criteriosa, inclusive para elas que talvez em outras ocasiões tivessem a entra franqueada, como pode ser observado no convite do baile de 1927 no qual constava: "para os socios servirá de ingresso o recibo do corrente mez e para as pessôas extranhas, inclusive senhoritas, serà, com todo rigor, exigido o respectivo convite" (DEMOCRATA CLUB, 1927, n. 2274, p. 2).

A existência de sedes sociais nesses clubes de futebol, somada à oferta de outros divertimentos, como ginástica, sala de jogos e biblioteca, possibilita pensar no propósito de possibilitar aos associados, inclusive as pessoas envolvidas diretamente com o futebol, um desenvolvimento físico, intelectual e moral, como era comum na época. Além disso, o fato de associados desses clubes disporem de um lugar comum para encontro e entretenimento pode se apresentar como um subsídio para o fortalecimento de uma vida esportiva na cidade, envolta por uma rede de sociabilidade constituída a partir do futebol.

Não é à toa que Rogerio de Alcantara, colunista do jornal Cidade de Barbacena, escrevia que o futebol era "o divertimento elegante de todas as sociedades" (ALCANTARA, 1918, n. 1428, p. 2). Tal afirmativa revela pistas sobre o prestígio dessa prática neste tempo e lugar, bem como faz pensar em pessoas envolvidas com esse divertimento, como, por exemplo, mulheres. 


\section{Participação das Mulheres de Barbacena no Futebol}

No Brasil, no início do século XX, o futebol foi vivenciado como um divertimento moderno, associado ao ideal de progresso dessa época, higiênico e salutar, ou seja, uma prática permitida e destinada à promoção da saúde (SOUTTO MAYOR, 2017; SOUZA NETO, 2010). Como um divertimento adotado fortemente pela elite, por isso nobre e distinto, permitiu aos homens estarem em campo e praticar o jogo e às mulheres, por serem consideradas fisiológica e socialmente inaptas para tais movimentos, foram concedidas outras formas de participação (GOELLNER, 1999, MELO, 2007).

Em Barbacena não parece ter sido muito diferente. A presença das mulheres no futebol foi observada em meio a times e campos de futebol: elas participaram na assistência dos jogos, como assistentes-espectadoras e assistentes-torcedoras, na demarcação do início de partidas, na premiação de equipes vencedoras e também como madrinhas de equipes.

A presença das mulheres na assistência, como espectadoras, pôde ser percebida já no dito primeiro jogo de futebol sediado em Barbacena, em 12 de outubro de 1904, entre o time local Hugo Braga Futebol Clube e o belo-horizontino Victor Serpa Futebol Clube (SAVASSI, 1991). Conforme relata Savassi (1991), ao resumir parte da obra de Murillo Meniconi, intitulada "Foot-Ball de Bahú...", o belo sexo barbacenense se posicionou de antemão ao jogo: elas não eram contra a realização da partida, todavia afirmaram que não iriam ao campo devido ao fato de os rapazes do Hugo Braga Futebol Clube "atuarem de calções curtos. Queriam que o nosso 'team' jogasse de calças 
compridas. Afinal, foi resolvido. Nem compridas, nem curtas. Meia canela" (SAVASSI, 1991, p. 222).

A importância das mulheres nessa partida de futebol pode ser destacada por alguns detalhes. As questões impostas por elas em relação à mudança no vestuário dos jogadores implica pensar pelo menos em duas situações: a de mulheres que por recato ou pudor, conforme princípios morais que eram ou deveriam ser observados por elas, não se sentiram à vontade em visualizar homens com pernas expostas correndo atrás de uma bola. Outra situação é a de que o narrador da partida Murilo Meniconi ou mesmo o memorialista Altair José Savassi poderiam ter intentado em demonstrar que era uma preocupação das mulheres daquela época afirmar em momentos públicos que tinham recato, ou seja, as barbacenenses que impuseram a mudança na indumentária dos jogadores podem ou não ter feito tal pedido devido a uma necessidade própria e da época, podendo apenas terem sido representadas dessa forma nesses textos escritos por homens.

Outro fato interessante é que para essa partida de 1904, os jogadores barbacenenses ao invés de descansarem na noite do dia 11 de outubro, "passaram-na cortando arvoredos e ramos, os quais fariam caramanchões para o belo sexo se abrigar ao Sol” (SAVASSI, 1991, p. 222). Tal fato evidencia a preocupação, por parte dos homens com as mulheres que compareceriam ao jogo, para que tivessem um lugar específico e com proteção contra os raios solares.

Vale ressaltar que nessa temporalidade era vigente a representação social que associava à mulher a delicadeza e a dependência de cuidados dos homens (GOELLNER, 1999; MALUF; MOTT, 1998; RAGO, 2004), de tal modo que se expor ao Sol poderia fisiologicamente comprometer o organismo feminino, por vezes entendido como de funcionamento frágil. Era necessário, pois, protegê-las. 
Ainda nessa mesma partida observou-se que, para além de participarem da assistência, uma mulher executou o "kick-off" do jogo, ou seja, o seu lance inicial, o qual foi efetuado pela "bonita e prendada senhorinha barbacenense Marieta Valle" (SAVASSI, 1991, p. 222). Aliás, uma mulher apta para a vida matrimonial, pois no início do século XX a atribuição de beleza para a mulher significava aptidão para gestar filhos bonitos e filhas bonitas, assim como ser prendada, significava ser entendida dos afazeres domésticos e conjugais (GOELLNER, 1999; SAN'TANNA, 2014).

As formas de participação das barbacenenses nessa partida somada às atitudes dos jogadores do Hugo Braga Futebol Clube de mudarem a indumentária do time, devido ao posicionamento das citadinas, além de prepararem um espaço adequado para as mesmas assistirem à partida corroboram em parte com os achados de Souza Neto (2010) que, ao estudar a prática do futebol em Belo Horizonte nos primórdios do século $\mathrm{XX}$, indica que a presença das belo-horizontinas na assistência do futebol como espectadoras era algo importante para a época, desde que conferisse caráter decorativo para as partidas. Segundo esse autor:

O caráter "décor" posto na funcionalidade da presença feminina aos jogos de futebol tendia a permanecer à medida que a lógica da assistência, distanciada da paixão clubística prevalecia nos "matches" de football. Obviamente a mulher representava, assim como uma banda de música, um atrativo atrelado à idéia do espetáculo esportivo, cada vez mais intensa, ainda na ausência de pertencimento clubístico (SOUZA NETO, 2010, p. 35).

Em parte, concordamos que as barbacenenses estiveram de forma decorativa no futebol, pois as atribuições conferidas a Marieta Valle na partida induzem a esse pensamento. Contudo, o fato da mesma ter dado o lance inicial do jogo, indica que a sua participação alterou a organização do prelio, o quê demonstra a importância das mulheres nesse contexto marcado por equipes constituídas por homens.

A participação "décor" das barbacenenses no futebol foi percebida em outros momentos e situações, como em uma partida realizada em 1917 entre o belo- 
horizontino America Foot-Ball Club e o Olympic Football Club, em que mulheres, como a senhorinha Noemia Marques, após o prelio, foi a responsável por oferecer um presente para a equipe vencedora, representando o bello sexo.

Como relata a matéria do jornal, mulheres novamente integraram momentos importantes do futebol barbacenense:

\begin{abstract}
Além de varias festas aqui realizadas, por occasião da Exposição Pecuniaria, há ainda a accrescentar a partida de jogo entre o "America Foot-Ball Club", de Bello Horizonte e o "Olympic Club" desta cidade.

Assistido por enorme multidão, teve logar o match, no campo proximo ao Collegio Militar, o qual terminou pela victoria alcançada pelo "America Club".

Terminado o combate, a senhorinha Noemia Marques, em bella ellocução, saudou o sportmen vencedor, offerecendo-lhe uma linda corbeille, em nome do bello sexo.

Abrilhantou a festa a banda do Batalhão, que alli compareceu tocando peças de seu magnifico repertorio (MATCH DE FOOT-BALL, 1917, n. 1320, p. $1)$.
\end{abstract}

Em 1918, no campo do Collegio Millitar, em uma disputa de futebol entre o Paysandú F.C. e o Olympic F.C., notou-se a participação de barbacenenses para além de “infalliveis assistentes dos matches", ou seja, assistentes-espectadoras, mas também como assistentes-torcedoras do futebol. Conforme relata o colunista:

O "football" que hoje, em dia, é o divertimento elegante de todas as sociedades, vai despertando, quotidianamente, crescente enthusiasmo entre nós e fazendo das nossas moças e dos nossos moços e, ainda, de velhos e crianças torcedores "enrangê" e infalliveis assistentes dos "matchs" [...] (ALCANTARA, 1918, n. 1428, p. 2).

Para Goellner (2014), a palavra torcedora designa o ato de mulheres, presentes em espaços de assistência aos jogos de futebol no início do século $\mathrm{XX}$, de retirarem as suas luvas pelo calor e pela emoção das pelejas e torcerem-nas: por isso o designativo torcedoras. Já para o cronista e dramaturgo Nelson Rodrigues (1993), o termo refere-se ao modo eufórico com que mulheres presentes em arquibancadas de encontros futebolísticos cariocas no início do século $\mathrm{XX}$ contorciam os seus corpos durante as 
partidas. O termo usado indica, para além de um envolvimento das mulheres com jogos de futebol, uma desestabilidade física e emocional por parte delas.

Sobre o termo torcedores "enrangê" acredita-se que possa se referir ao termo inglês enranged, traduzido como enfurecido (DICIONÁRIO BAB.LA, s.d.); ou francês enrager que significa enraivecer, tirar a paciência, encolerizar-se; ou enrageant, traduzido como o que causa raiva (LAROUSSE, s.d). Desse modo, pode se observar que a participação das mulheres não era inerte ou secundária às ações dos homens que também compunham a assistência das partidas, pois torcer enfurecidamente ou enraivecidamente demonstra sentimento e envolvimento com o que está acontecendo; indica atuação efetiva no contexto da partida, embora não seja correndo atrás da bola com a intenção de alcançar o centro das balizas e pontuar gol.

Apresentar as mulheres como torcedoras "enrangê" diz de uma maior consolidação da presença das mesmas no espaço do futebol barbacenense, significando que não se tratavam de meras assistentes no entorno das partidas, isto é, necessariamente não estavam de forma estática nos tempos dos jogos.

Ademais, "muitas senhoras" estiveram na assistência dos campos de futebol como espectadoras (FOOT-BALL, 1926, n. 2216, p.2), contudo foram as mulheres jovens, citadas em alguma ocasiões como moças e em outras como senhorinhas ou senhoritas, que se destacavam nas participações ou que foram além de assistir aos prelios ludopedicos. Mais do que isso, "o elemento feminino foi realçado de maneira encantadora" (FOOT-BALL, 1919, n. 1542, p. 2) não somente na assistência, como espectadoras e torcedoras, ou integrando a abertura das partidas e premiando equipes vencedoras, mas também como madrinhas de times de futebol da localidade.

Madrinha significa "a mulher que vae tocar na criança, que se baptisa, a que assiste a noiva na Igreja [...], a que patrocina" (PINTO, 1832, s. p.). Desse modo, ser 
madrinha de um time de futebol pode fazer referência a responsabilidades de uma mulher de uma dada associação esportiva e que tem, sobretudo, o papel de representá-la de alguma forma, como financeira e socialmente, de maneira eventual ou constante.

Essa forma de participação pode, inclusive, ter alargado ainda mais as possibilidades das barbacenenses integrarem atividades relacionadas ao futebol, visto que as madrinhas podem ter participado mais ativamente de outras ações dos times, como as esportivas e sociais.

Além disso, elas pode ter consequentemente influenciado a forma como outras citadinas se divertiam nos jogos devido à possibilidade de as madrinhas, mesmo que representando uma equipe formada por homens, retratarem de forma pontual, dentro desse esporte, questões referentes ao seu sexo, o que pode ter refletido em novas configurações das formas de participação das mulheres no futebol barbacenense.

Como as madrinhas existiam também os patronos. Ambos, de alguma forma, relacionavam entre si. Na programação de um torneio interno denominado Torneio Initium que ocorreu em sua sede, no campo do Morro de Santa Thereza, e que foi promovido pelo próprio Olympic $F$. $C$. em 1928 , e identificaram-se times que contavam com a participação de senhoritas como madrinhas e de homens como patronos, esses os quais tiveram os seus nomes dados às respectivas equipes por eles protegidos, como aparece abaixo na relação das madrinhas desse torneio:

[...] Os teams, seus patronos e madrinhas

TEAM DR. ELOY CAMARA

Madrinha: Senhorita Odette Godinho

Carlos, Dario, Mazico, Betinho, Orestes (cap.), Fabio, Oswaldo, Domingos, Dolabella, Maia, Tinduca

TEAM JOSÉ FRANCISCO ANTUNES

Madrinha: Senhorita Celuta Mello

Halley, Sandico, Alonso, Lima, Renault, Vasco, Mario (cap.), Zezinho, Synval, Amadeu, Paulo

TEAM EMMANOEL TAVEIRA

Madrinha: Senhorita Juracy Moreira Machado 
Cyro (cap.), Verçosa, Aristoteles, Russo, Chedid, Waldemar, Matta, Pirolito, Cecy, Mozart

\section{TEAM ADHEMAR DE SOUZA}

Madrinha: Senhorinha Maria Braga

Sarmento, Jaburú, Arlindo, Moacyr, Gastão, Manoel, Fonseca, Luiz, Tellinho, Affonso (cap.) Simão [...] (CALVO, 1928, n. 2428, p. 2).

Será qual o sentido de times terem patronos e madrinhas? Seriam papeis similares, mesmo que para diferentes sexos? Abaixo segue uma imagem desse torneio de 1928, do team de Emmanoel Taveira junto a sua madrinha (FIGURA 3):

\section{Figura 3: Team Emmanoel Taveira e sua madrinha (1928) 17.}

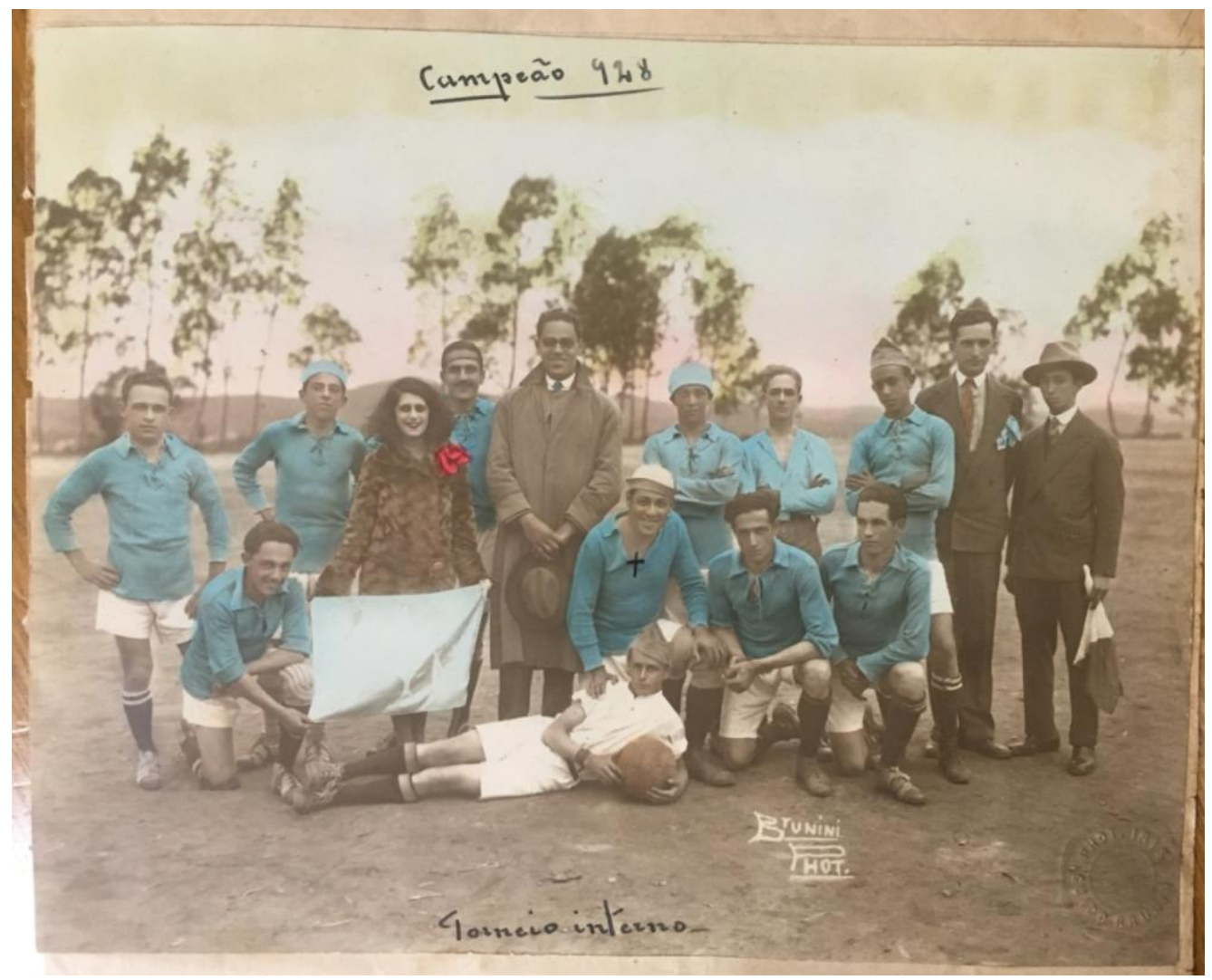

Fonte: Acervo pessoal da família de Cyro Duque Estrada.

No ano anterior, em 1927, nesse mesmo torneio interno não constava a presença de patronos para os times, somente de madrinhas cujos nomes foram dados às respectivas equipes, como pode ser verificado na matéria abaixo:

17 Cyro Duque Estrada encontra-se ao lado do homem com chapéu na mão (Emmanoel Taveira?), de cócoras, com um sinal de cruz desenhado na gola de sua camisa. 
Foot-ball

Terá inicio hoje o campeonato interno do "Olympic Club", devendo ser o primeiro jogo disputado às 9 horas

A directoria do Olympic organizou um interessante Campeonato Interno, que terá inicio hoje com o <<Torneio Initium $>>$.

Estão organizados quatro teams, cujas forças parecem bem equilibradas.

Team senhorinha Aracy Esteves

Carlinhos - Dario - Ninico - Odilon - Cyro - Lima - Vianna - Sinhô Celso - Gastão - Waldemar

Capitão - Cyro Duque Estrada

Team senhorinha Celia de Queiroz

Ernesto - Affonso - Telinho - Waldemar - Domingos - Malta - Lauro Totó - Tatão - Arlindo - Chedid

Capitão - Sebastião Ribeiro Mendes (Tatão)

Team senhorinha Yáyá Moreira

Brasil - Mozart - Synval - Lulú - Mario - Fabio - Argentino - Garizo Cecy - Leopoldo - Lopes

Capitão - Mario F. Gomes

Team senhorinha Carmen Fontana Paulucci

Paulo - Claudio - Lindolpho - Mazico - Orestes - Orpheu - Ary - Sandico Guilherme - Betinho - Geraldo

Capitão - Guilherme Menezes

$\mathrm{O} \ll$ Torneio $\gg$ terá inicio ás 9 horas, devendo obedecer ao seguinte programma:

$1^{\circ} \mathrm{JOGO}$

Celia de Queiroz e Yaya Moreira

$2^{\circ} \mathrm{JOGO}$

Aracy Esteves e Carmen Paulucci

$3^{\circ} \mathrm{JOGO}$

Vencedor do $1^{\circ} x$ Vencedor do $2^{o}$

Os juizes serão escolhidos pelos captains dos teams dos disputantes. Os captains dos quatro teams concurrentes, constituirão o Conselho Divisional, cujas decisões estarão sempre sujeitas à aprovação da Directoria do Olympic Club, que terá as funcções de Conselho Superior.

O ingresso no campo, tanto para o Torneio como para os matchs de <<Campeonato〉> será gratuito (CALVO, 1927, n. 2335, p. 2).

Será que as mesmas desempenharam alguma função que até então era conferida apenas aos patronos e não a elas? Observa-se que as mulheres neste torneio interno tiveram um maior pertencimento sobre os times que amadrinharam, pois a imprensa 
anunciou que elas formaram equipes de "torcedoras para as suas cores" (CALVO, 1927, n. 2337, p. 2).

O termo "suas cores" sugere posse, ou seja, as cores dos times que representavam, empenhando-se, por exemplo, para mobilizar novas torcedoras. Isso porque a imprensa ressaltou que esse torneio foi um momento em que se privilegiou a presença das mulheres, uma vez que "os jogos de domingo attrahiram regular concurrencia ao ground de Santa Thereza, predominando n'ella o Elemento feminino" (CALVO, 1927, n. 2339, p. 1).

Além disso é interessante observar que elas desempenharam outras atuações no grupo, como ocorre com Aracy Esteves, uma das madrinhas do torneio interno de 1927, que em 1926 aparece como torcedora do OlympicF.C. e participante de uma prova de athletismo que antecedeu ao jogo entre Olympic e "Atheltico" no ground do Morro de Santa Thereza (FOOT-BALL, 1926, n. 2216, p. 2). Conforme relata o jornal:

[...] Constituiram a nota mais interessante do festival as corridas com obstaculos18, dos quaes compartilharam graciosamente alegres e elegantes $<<$ torcedoras $>>$. Venceram nelas as senhorinhas Aracy Esteves, Clydéa Tavares, Lynce e Sevigné Henriques e Daura Rodrigues. Aos vencedores foram entregues, em seguida, os bellos premios offerecidos pelos patronos das provas, recebendo-os aquelles das mãos da gentil senhorinha Iracema Pereira da Silva que é madrinha do segundo team official do <<Olympic〉> [...] (FOOT-BALL, 1926, n. 2216, p.2).

Será que os fatos de Aracy Esteves ser torcedora do Olympic e uma das vencedoras da prova de athletismo de 1926 influenciaram para a sua elevação ao posto de madrinha em 1927? E as outras vencedoras da mesma prova, como Clydéa Tavares, Lynce e Sevigné Henriques e Daura Rodrigues, por que não foram também madrinhas de times de futebol em $1927 ?$

São muitas as perguntas, como: qual o critério para escolha de uma madrinha? Qual representação a mesma poderia e deveria conferir a sua equipe? Para ser madrinha 
era necessário vigor físico assim como era desejado para os jogadores? Para ser madrinha era necessário se destacar na assistência e mobilização da torcida? Seriam as madrinhas de famílias abastadas da região, sendo esse um parâmetro para a escolha das mesmas para essa posição? Existiam concursos para a eleição de madrinhas? Estariam essas mulheres em posição de destaque na sociedade barbacenense e, por isso, eram escolhidas para ocupar essa posição? Seriam essas madrinhas parte de um grupo específico de Barbacena envolvido com divertimentos, pois mulheres como Carmen Fontana (UMA FESTA DE ARTE, 1917, n. 1319, p. 1), Aracy Esteves, Yaya Moreira (FESTA DO BEM-ME-QUER, 1926, n. 2253, p. 1) e Juracy Moreira19 organizaram e integraram apresentações artísticas de música, teatro e dança no início do século XX, revelando a participação das mulheres, não só no futebol, mas em diferentes âmbitos e práticas. Ou, seria a beleza o principal critério para a elevação de uma mulher ao posto de madrinha? Se sim, qual beleza era exigida? São questões que ficam.

Para mais, as mulheres que participavam dos divertimentos anunciados pela imprensa em Barbacena eram, sobretudo, pertencentes aos estratos sociais mais privilegiados economicamente. Todavia, há indícios de que em Barbacena, nesse marco temporal, o futebol foi um divertimento acessível, no que tange a presença de pessoas de diferentes classes sociais e de diferentes faixas etárias na assistência das partidas como público espectador, pois não foram encontradas informações explícitas sobre a cobrança de ingressos para o acesso aos campos de futebol da cidade em dias de jogos, o que pode ser um indicativo importante da não restrição da participação de pessoas de outras classes econômicas nos campos em dias de jogos.

\section{Considerações Finais}

19 THEATRO S. JOSÉ, 25 fev. 1932..; THEATRO S. JOSÉ, 29 mar. 1932 ...; CINE THEATRO BRASIL, maio de 1940. 
O futebol em Barbacena nas primeiras décadas do século XX manifestou-se de diferentes formas: times, clubes, campos e partidas.

As mulheres participaram na assistência aos jogos como espectadoras e torcedoras, na demarcação do início de partidas, na premiação das equipes vencedoras, como madrinhas de times e, possivelmente, de outras formas ainda não identificadas. Acredita-se que essas formas de participação não se opuseram ou se permutaram, mas que podem ter acontecido ao mesmo tempo.

Em um divertimento que até os dias atuais é compreendido como esporte para ser praticado especialmente por homens, uma vez que ainda há muita resistência e preconceito social e midiático com o futebol jogado por mulheres, percebe-se que participar é algo plural, não significando apenas conduzir a bola ao fundo da baliza, mas também estar presente, interagir com outras pessoas, integrar-se ao cenário e às ações; representar, assistir, torcer, se emocionar.

O futebol em Barbacena no início do século XX é ainda um tema que carece de investigações. As atividades do Olympic Football Club, por exemplo, em que o futebol é central, merecem atenção, pois esta agremiação está em atividade na cidade somando mais de cem anos de existência e as mulheres estão presentes em suas ações desde o início de suas atividades.

Este trabalho apresenta contribuições para estudos sobre história dos divertimentos, das mulheres, de Barbacena e do futebol. Como limite, não foram encontradas indicações de proibição da participação das mulheres como jogadoras, embora essa ainda seja uma realidade comum à época ou, até então, comumente retratada pela historiografia. 


\section{REFERÊNCIAS}

AlCANTARA, R. Sociaes. Cidade de Barbacena, Barbacena, n. 1428, p. 2, 20 jun. 1918.

ALVES, R. O. T. A lucta dos titans: a invenção da rivalidade entre Clube Atlético Mineiro e a Sociedade Sportiva Palestra Italia: 1921-1942. Dissertação (Mestrado) Escola de Educação Física, Fisioterapia e Terapia Ocupacional, Universidade Federal de Minas Gerais, 2013.

AMARAL, D. V. de O. "À mania intoxicadora": introdução clubística e consolidação dos sentidos de competitividade do foot-ball no centro-oeste mineiro (1888-1930). 2016. 177 f. Dissertação (Mestrado) - Departamento de Ciências Sociais, Políticas e Jurídicas, Universidade Federal de São João el-Rei, São João del-Rei, 2016.

.; DIAS, C. Nos trilhos do lazer: entretenimento urbano e mercado de diversões em Divinópolis, Minas Gerais, 18901920. Revista de História Regional, Ponta Grossa, 22(2): 237-261, 2017. Disponível em: https://www.revistas2.uepg.br/index.php/rhr/article/view/10512 Acesso em: 15 fev. 2019.

ARBEX, D. O holocausto brasileiro: vida, genocídio e 60 mil mortes no maior hospício do Brasil. São Paulo: Geração Editorial, 2013. 272 p.

BARROS, C. S. Luz e progresso: o imaginário da Belle Époque em Juiz de Fora (18891914). In: COLÓQUIO DO LAHES, I, 2005, Juiz de Fora. Anais... Juiz de Fora: Laboratório de História Econômica e Social, 2005, p. 1-13. Disponível em: https://www.ufjf.br/lahes/files/2010/03/c1-a11. pdf. Acesso: 2 out. 2017.

Eletricidade como elemento de modernização em Juiz de Fora (1889-1915).

Revista de História Econômica \& Economia Regional Aplicada. Juiz de Fora, v. 3, n. $5, \quad$ p. 26-52, jul.-dez. 2008. Disponível em: https://www.ufjf.br/heera/files/2009/11/artigo_2.pdf Acesso: 16 mar. 2018.

BLOCH, M. Apologia da história ou o ofício do historiador. Rio de Janeiro: Jorge Zahar Editor Ltda, 2001. 159 p.

CALVO. Secção Sportiva. Cidade de Barbacena, Barbacena, n. 1894, p. 2, 17 mai. 1923.

. Secção Sportiva. Cidade de Barbacena, Barbacena, n. 2299, p. 2, 2 jun. 1927.

Secção Sportiva. Cidade de Barbacena, Barbacena, n. 2335, p. 2, 9 out. 1927.

CALVO. Secção Sportiva. Cidade de Barbacena, Barbacena, n. 2337, p. 2, 16 out. 1927. 1927.

Secção Sportiva. Cidade de Barbacena, Barbacena, n. 2339, p. 1, 22 out. Foot-ball. Cidade de Barbacena, Barbacena, n. 2428, p. 2, 8 set. 1928. 
CAMPOS, P. A. F. Mulheres torcedoras do Cruzeiro Esporte Clube presentes no Mineirão. 2010. 142 f. Dissertação (Mestrado) - Escola de Educação Física, Fisioterapia e Terapia Ocupacional, Universidade Federal de Minas Gerais, Belo Horizonte, 2010.

CIMINO, M. S. S. Iluminar a terra pela inteligência: trajetória do aprendizado agrícola de Barbacena, MG (1910-1933). 2013. 371 f. Tese (Doutorado), Faculdade de Educação, Universidade do Estado do Rio de Janeiro, Rio de Janeiro, 2013.

COUTO, E. F. Belo Horizonte e o futebol: integração social e identidades coletivas (1897-1927). Dissertação (Mestrado) - Faculdade de Ciências Sociais, Universidade Católica de Minas Gerais, Belo Horizonte, 2003.

CUNHA JUNIOR, C. F.; MORORÓ, A.; LISBOA, J. D. M.; SOARES, P. G. Esporte e práticas corporais em Juiz de Fora (1876-1915). In: CUNHA JUNIOR, C. F. (Org.). Histórias e memórias do esporte em Minas Gerais. Juiz de Fora: Editora UFJF, 2011. p. 11- 29.

DE LUCA, T. R. História dos, nos e por meio dos periódicos. In: PINSKY, C. B. (Org.). Fontes Históricas. 3. ed. São Paulo: Contexto, 2011. p. 111-153.

DEL PRIORE, M. História da gente brasileira: República. Memórias (1889-1950). Rio de Janeiro: LeYa, 2017. v. 3. 544 p.

DEMOCRATA Club. Cidade de Barbacena, Barbacena, n. 2274, p. 2, 24 fev. 1927.

DIAS, C. et al. História do futebol em Minas Gerais. Tempos Gerais - Revista de Ciências Sociais e História, São João del-Rei, v.3, n. 2, p. 67-86, 2014.

DICIONÁRIO BAB. LA. Disponível em: http://pt.bab.la. Acesso: 19 ago. 2019.

DIPLOMA. 25 jul. 1957. Acervo da família Duque-Estrada.

DUARTE, R. H. Noites Circenses: espetáculos de circo e teatro em Minas Gerais no século XIX. Campinas: Editora da UNICAMP, 1995, 279 p.

FESTA DO BEM-ME-QUER. Cidade de Barbacena, Barbacena, n. 2253, p. 1, 12 dez. 1926.

FOOT-BALL. Cidade de Barbacena, Barbacena, n. 1542, p. 2, 26 out. 1919.

Cidade de Barbacena, Barbacena, n. 1814, p.1, 3 ago. 1922.

Cidade de Barbacena, Barbacena, n. 2216, p.2, 1 ago. 1926.

GOELLNER, S. V. Mulheres e futebol: entre bolas e bonecas, a dificuldade de inserção. Revista Pré-Univesp, São Paulo, p. 1-3, jun. 2014.

"As mulheres fortes são aquelas que fazem uma raça forte": esporte, eugenia e nacionalismo no Brasil no início do século XX". Recorde: Revista de História do Esporte, Rio de Janeiro, v. 1, n. 1, p. 1-28, jun. 2008. Disponível em: http://revistas.ufrj.br/index.php/Recorde/article/view/790 Acesso: 20 fev. 2018. 
Bela, maternal e feminina: imagens da mulher na Revista Educação Physica. 1999. 194 f. Tese (Doutorado) - Faculdade de Educação, Universidade Estadual de Campinas, Campinas, 1999.

LAROUSSE. Dicionário de língua francesa. Disponível em: http://www.larousse.fr/dictionnaires/francais/enrager/29726?q=enrager\#29616 Acesso: 19 ago. 2019.

LE GOFF, J. História e memória. 7. ed. Revista. Campinas: Editora da UNICAMP, 2013. 499 p.

LIMA, A. W. O Jogo de bola em terras mineiras: uma comparação entre a institucionalização do futebol em Belo Horizonte e São João del-Rei (1904 - 1921). Dissertação (Mestrado) - Instituto de Filosofia e Ciências Sociais, Universidade Federal do Rio de Janeiro, Rio de Janeiro, 2014.

LUCENA, R. F. O esporte na cidade: aspectos do esforço civilizador brasileiro. Campinas: Autores Associados, 2001. 103 p.

MALUF, M.; MOTT, M. L. Recônditos do mundo feminino. In: SEVCENKO, N. História da vida privada no Brasil. São Paulo: Companhia das Letras, 1998. v. 3. p. $368-421$.

MASSENA, N. Barbacena: a terra e o homem. Belo Horizonte: Imprensa Oficial, 1985. v. 2. 268 p.

MATCH de foot-ball. Cidade de Barbacena, Barbacena, n. 1320, p. 1, 13 mai. 1917.

MELO, V. A. Cidade sportiva: primórdios do esporte no Rio de Janeiro. Rio de Janeiro: Relume Dumará: FAPERJ, 2001. 235 p.

Mulheres em movimento: a presença feminina nos primórdios do esporte na cidade do Rio de Janeiro (até 1910). Revista Brasileira de História, São Paulo, v. 27, n. 54, p. 127-152, 2007. Disponível em: https://www.scielo.br/pdf/rbh/v27n54/a08v2754.pdf . Acesso: 21 fev. 2018.

MICHAELIS. Dicionário Brasileiro da Língua Portuguesa. 2019. Disponível em: https://michaelis.uol.com.br/moderno-portugues/busca/portugues-brasileiro/duquesa/.

Acesso: 10 ago. 2019.

MOURA, R. C. B. O amadorismo, o profissionalismo, os sururus e outras tramas: o futebol em Belo Horizonte nas décadas de 1920 e 1930. Dissertação (Mestrado) Escola de Educação Física, Fisioterapia e Terapia Ocupacional, Universidade Federal de Minas Gerais, Belo Horizonte, 2010.

PIMENTA, E. F. Duas faces de uma mesma moeda: recepção e circulação do ideário fascista e integralista em Barbacena-MG através do casal Ines e Aroldo Piacesi, 19241945. 2015. 362 f. Dissertação (Mestrado) - Universidade Federal de São João del Rei, São João del Rei, 2015. 
PINTO, L. M. da S. Diccionario da Lingua Brasileira por Luiz Maria da Silva Pinto, natural da Provincia de Goyaz. Na Typographia de Silva, 1832. Disponível em: https://dicionarios.bbm.usp.br/pt-br/dicionario/3/madrinha Acesso: 03 abr. 2018.

RAGO, M. Trabalho feminino e sexualidade. In: DEL PRIORE, M. (Org.); BASSANEZI, C. (coord. de textos). História das mulheres no Brasil. São Paulo: Contexto/Ed. UNESP, 2004. p. 578-606.

RIBEIRO, R. R. A bola, as ruas alinhadas e uma poeira infernal: os primeiros anos do futebol em Belo Horizonte (1904-1921). Belo Horizonte: Drible de Letra, 2018.

RESSAQUINHA. A folha, Barbacena, APM, JM-1234655, edição: 43 - 06/07/1893, p.3.

RESENDE, E. M. Do debate político à notícia: a imprensa periódica em Barbacena séculos XIX e XX. Revista Mal-Estar e Sociedade, Barbacena, Ano V, n. 8, p. 15-40, jan./jun. $2012 . \quad$ Disponível em: https://revista.uemg.br/index.php/malestar/article/view/185 Acesso: 24 dez. 2017.

RODRIGUES, M. A. A. Constituição e enraizamento do esporte na cidade: uma prática moderna de lazer na cultura urbana de Belo Horizonte (18941920). 2006. 340 f. Tese (Doutorado) - Faculdade de Filosofia e Ciências Humanas, Universidade Federal de Minas Gerais, Belo Horizonte, 2006.

RODRIGUES, N. Flamengo sessentão. In: RODRIGUES, N. À sombra das chuteiras imortais: crônicas de futebol. São Paulo: Companhia das Letras, 1993. p 13-15.

SAN'TANNA, D. B. História da beleza no Brasil. São Paulo: Contexto, 2014. 205 p.

SAVASSI, A. J. Barbacena 200 anos. Belo Horizonte: Editora Lemi S.A, 1991. v. 1. $287 \mathrm{p}$.

SEVCENKO, N. Orfeu extático na metrópole: São Paulo, sociedade e cultura nos frementes anos 20. São Paulo: Companhia das Letras, 1992. 390 p.

SILVA, S. P. Considerações sobre o relacionamento amoroso entre adolescentes. Cad. Cedes, Campinas, v. 22, n. 57, p. 23-43, ago. 2002. Disponível em: https://www.scielo.br/scielo.php?pid=S010132622002000200003\&script=sci_abstract\& tlng=pt Acesso: 13 mar. 2019.

SILVA, L. P. Em nome da modernidade: uma educação multifacetada, uma cidade transmutada, um sujeito inventado (Montes Claros, 1889-1926). 2012. 212 f. Tese (Doutorado) - Faculdade de Educação, Universidade Federal de Minas Gerais, Belo Horizonte, 2012.

SILVA, I. M. Elas se divertem (Barbacena - MG, 1914 a 1931). 2018. $136 \mathrm{f}$. Dissertação (Mestrado) - Escola de Educação Física, Fisioterapia e Terapia Ocupacional, Universidade Federal de Minas Gerais, Belo Horizonte, 2018.

.; LIMA, C. D. M. D. A bola rolando no "Triângulo": apontamentos sobre a história regional do futebol no Triângulo Mineiro e seus diálogos com São Paulo no início do século XX. Vozes, Pretérito \& Devir: Revista de História da UESPI, Piauí, 
Ano IV, v. V, n. I, 2016. Disponível em: https://revistavozes.uespi.br/ojs/index.php/revistavozes/article/view/97/110 Acesso: 14 mar. 2019.

SILVA, I. M. Lindas, bonitas, gentis e graciosas nos divertimentos, práticas corporais e esportivas (Uberlândia e Uberaba - MG, 1918- 1943). Vozes, Pretérito \& Devir: Revista de História da UESPI, Piaú, Ano IV, v. VII, n. I, 2017. Disponível em: https://revistavozes.uespi.br/ojs/index.php/revistavozes/article/viewFile/145/164 Acesso: 15 mar. 2019.

SIMMEL, G. Sociabilidade, um exemplo de sociologia pura ou formal. In: MORAIS FILHO, E. de. Georg Simmel. Sociologia. São Paulo: Ática, 1983. p. 165-181.

SOARES, P. G. Práticas corporais e diversão em Juiz de Fora/MG: o discurso do jornal O Pharol (1876-1915). 2010. 133 f. Dissertação (Mestrado) - Faculdade de Educação, Universidade Federal de Juiz de Fora, Juiz de Fora, 2010.

História das práticas corporais e diversão na zona da mata mineira: indícios a partir da imprensa de Cataguases/MG e Juiz de Fora/MG. Licere, Belo Horizonte, v. 21, n. 4, dez. 2018. Disponível em: https://file:///C:/Users/Igor\%20Silva/Downloads/1947-Texto\%20do\%20artigo-5941-110-20181223.pdf Acesso: 24 ago. 2019.

SOCIAES. Cidade de Barbacena, Barbacena, n. 2645, p. 3, 7 jan. 1931.

SOUTTO MAYOR, S. T. O futebol na cidade de Belo Horizonte: amadorismo e profissionalismo nas décadas de 1930 e 1940. 2017. 359 f. Tese (Doutorado) - Escola de Educação Física, Fisioterapia e Terapia Ocupacional, Universidade Federal de Minas Gerais, Belo Horizonte, 2017.

SOUZA NETO, G. J. A invenção do torcer em Belo Horizonte: da assistência ao pertencimento clubístico (1904-1930). 2010. 130 f. Dissertação (Mestrado) - Escola de Educação Física, Fisioterapia e Terapia Ocupacional, Universidade Federal de Minas Gerais, Belo Horizonte, 2010.

TRINDADE, E. Cidade moderna e espaços femininos. Projeto História. Revista do Programa de Estudos Pós-Graduados de História, São Paulo, v. 13, p. 109-120, jun. 1996. Disponível em: http://revistas.pucsp.br/index.php/revph/article/view/11260 Acesso em: 13 mar. 2019.

UMA FESTA DE ARTE. Cidade de Barbacena, Barbacena, n. 1319, p. 1, 9 maio 1917.

ZICMAN, R. B. História através da imprensa: algumas considerações metodológicas. Projeto História. Revista do Programa de Estudos Pós-Graduados de História, São Paulo, v. 4, p. 89-102, 1985. Disponível em: http://revistas.pucsp.br/index.php/revph/article/view/12410 Acesso em: 18 nov. 2017. 


\section{Endereço dos Autores:}

Igor Maciel Silva

EEFFTO/UFMG

Av. Antônio Carlos 6627 - Pampulha

Belo Horizonte - MG - 31270-901

Endereço Eletrônico: professorigormaciel@gmail.com

Maria Cristina Rosa

EEFFTO/UFMG

Av. Antônio Carlos 6627 - Pampulha

Belo Horizonte - MG - 31270-901

Endereço Eletrônico: m.crosa@hotmail.com 